\title{
The PDE4 inhibitor rolipram reverses object memory impairment induced by acute tryptophan depletion in the rat
}

\author{
K. Rutten • C. Lieben $\cdot$ L. Smits • A. Blokland
}

Received: 4 October 2006 / Accepted: 28 December 2006 / Published online: 30 January 2007

(C) Springer-Verlag 2007

\begin{abstract}
Rationale The selective type IV phosphodiesterase inhibitor, rolipram, has been shown to improve long-term memory and can reverse the cholinergic deficit caused by scopolamine. However, the underlying mechanisms of action of rolipram remain obscure.

Objectives The present study investigates the effect of rolipram in a serotonergic-deficit model of acute tryptophan depletion (ATD). In addition, the levels of plasma tryptophan (TRP) were compared to object recognition performance.

Materials and methods The experiments were conducted using male Wistar rats. The time-dependent effect of ATD treatment (a gelatin-based protein mixture) on plasma TRP levels $(0,1,3$, and $6 \mathrm{~h}$ after injection) and object recognition task (ORT) performance $(0.5,1,3$, and $6 \mathrm{~h}$ after ATD treatment) was examined. The effect of rolipram $(0,0.01,0.03$, and $0.1 \mathrm{mg} / \mathrm{kg}$, i.p. $)$ was tested in the condition in which ATD induced a clear memory deficit.

Results ATD significantly lowered the plasma TRP ratio (TRP/ $/$ large neutral amino acid) with a maximum of $48 \%$, approximately $1 \mathrm{~h}$ after administration. Furthermore, ATD
\end{abstract}

K. Rutten $(\varangle) \cdot$ L. Smits

Department of Psychiatry and Neuropsychology,

Brain and Behavior Institute, Maastricht University,

Universiteitssingel 50,

P.O. Box 616 ,

6200 MD Maastricht, The Netherlands

e-mail: k.rutten@np.unimaas.nl

C. Lieben

Department of Surgery, Maastricht University,

Maastricht, The Netherlands

\section{A. Blokland}

Department of Psychology, Brain and Behaviour Institute,

Maastricht University,

Maastricht, The Netherlands impairs ORT performance when administered $3 \mathrm{~h}$ before testing. Rolipram $(0.1 \mathrm{mg} / \mathrm{kg})$ reversed the memory deficit induced by ATD in a dose-dependent manner.

Conclusions On the basis of previous studies and the ability to reverse a serotonergic deficit, we suggest that rolipram may act through elevation of cyclic adenosine monophosphate levels and subsequent increase in neurotransmitter release.

Keywords Phosphodiesterase · PDE4 - Rolipram · Tryptophan depletion · Cognition · Cyclic AMP. Memory $\cdot$ Object recognition $\cdot$ ATD

\section{Introduction}

Inhibition of phosphodiesterase type 4 (PDE4) leads to an increase in intracellular cyclic adenosine monophosphate (cAMP) availability (Silvestre et al. 1999). cAMP is an important second messenger molecule in the process of intracellular signal transduction mechanisms (Bailey et al. 1996). Several studies have shown that rolipram, a selective PDE4 inhibitor, improves cognitive performance in young rats (Blokland et al. 2006; Imanishi et al. 1997; Rose et al. 2005; Zhang et al. 2000, 2004) and ameliorates scopolamine-induced memory deficits (Egawa et al. 1997; Imanishi et al. 1997; Rutten et al. 2006; Zhang and O'Donnell 2000).

In a previous study, we have shown that rolipram reversed a scopolamine-induced deficit in an object recognition task (ORT) in male Wistar rats (Rutten et al. 2006). It was suggested that these effects may be related to the effects of elevated cAMP levels on neurotransmitter release. There is also evidence that there is a link between PDE4 inhibition and serotonergic neurotransmis- 
sion (Schoffelmeer et al. 1985; West and Galloway 1996). The adenylate cyclase activator forskolin, as well as 8bromo-cAMP, can enhance the electrically evoked release of ${ }^{3} \mathrm{H}$-5-hydroxytryptamine (Schoffelmeer et al. 1985). Thus, elevating cAMP levels by a selective PDE4 inhibitor could exert a general facilitatory effect on 5-HT release. Based on these findings, we argued that rolipram may also reverse memory deficits induced by a lowered 5-HT neurotransmission.

Acute tryptophan depletion (ATD) is a well-established model to assess the role of serotonin in cognitive and affective functioning (Booij et al. 2003). The neurotransmitter serotonin is synthesized from its amino acid precursor tryptophan (TRP), which is obtained from our food. Free TRP is transported into the brain across the blood-brain barrier, but has to compete for entrance with five other large neutral amino acids (LNAAs: valine, leucine, isoleucine, phenylalanine, and tyrosine). The ratio of TRP and these other LNAAs (TRP/ $/$ LNAA ratio) is thought to be a more sensitive index of brain TRP availability (Fernstrom 1981; Wurtman et al. 1980). As 5HT is synthesized from TRP, through the rate-limiting enzyme TRP-hydroxylase, the availability of TRP in the brain determines the amount of central 5-HT (Wurtman et al. 1980). Due to its reversible and non-intrusive effects, the method of ATD can be repeatedly used in animals and humans.

In humans, acute tryptophan depletion has a negative effect on memory consolidation (Park et al. 1994; Riedel et al. 1999; Schmitt et al. 2000). Furthermore, memory impairments in the ORT have been observed in rats after ATD (Lieben et al. 2004b, 2005). Therefore, we hypothesized that rolipram could reverse an ATD-induced memory deficit in rats by elevating 5-HT release in the brain.

In addition to this aim of the study, we further examined the relation between peripheral TRP and memory performance. We investigated the effects of different pretreatment times of the TRP-depleted mixture on object recognition memory. These data should provide more experimental support for a relation between plasma TRP and, consequently, central 5-HT and memory performance.

\section{Materials and methods}

Animals

All experimental procedures were approved by the local ethical committee of the Maastricht University for animal experiments according to governmental guidelines. A total of 42 4-month-old male Wistar rats (Charles River, The Netherlands) were used $(410-450 \mathrm{~g})$. Rats were randomly assigned to either the biochemistry $(n=18)$ or the behavior group $(n=24)$. In the biochemistry groups, the animals were randomly subdivided over three treatment groups, i.e., saline, TRP + , or TRP $-(n=6 /$ group $)$. The animals were housed individually in standard type 3 Makrolon cages on sawdust bedding in an air-conditioned room (about $20^{\circ} \mathrm{C}$ ). They were kept under a reversed 12/12-h light/dark cycle (lights on from 18:00 to 6:00 hours) and had free access to water. Rats were housed in the same room as where they were tested. A radio, which played softly, provided background noise in all rooms. All testing were done between 9:00 and 17:00 hours.

Drugs and chemicals

The gelatin hydrolysate (Solugel C) was obtained from PB Gelatins (Tessenderlo, Belgium). Glucodry 210 was obtained from the Amylumgroup (Koog aan de Zaan, The Netherlands). L-Tryptophan and rolipram were obtained from Sigma-Aldrich (Zwijndrecht, The Netherlands). Kaliumchloride $(\mathrm{KCl})$, calciumchloride-dihydrate $\left(\mathrm{CaCl}_{2} \cdot 2 \mathrm{H}_{2} \mathrm{O}\right)$, and 5-sulfosalicylic acid dihydrate were purchased from Merck (Darmstadt, Germany).

\section{Treatment}

During a period of 2 weeks preceding the experiment, the rats were handled and habituated to oral injections with normal tap water $(10 \mathrm{ml} / \mathrm{kg})$. On experimental days, the rats were not fed $14 \mathrm{~h}$ before treatment until the testing period was completed. This was done to minimize the availability of TRP from food, which would counteract the effects of the ATD treatment. The rats were orally treated with a protein-carbohydrate mixture containing TRP (TRP+ group; in which $0.28 \%$ TRP of the total protein was added to the mixture) or one lacking TRP (TRP- group; no TRP added to the mixture), or with saline. The composition of the nutritional mixture is shown in Table 1.

In every experiment, each dose contained Solugel $\mathrm{C}$ at $4.0 \mathrm{~g} / \mathrm{kg}$ and Glucodry at $2.0 \mathrm{~g} / \mathrm{kg}$ of the body weight and was given in a dose of $10 \mathrm{ml} / \mathrm{kg}$ between $8: 30$ and 12:30 hours. Blood samples were taken at baseline (20 min before treatment) and 60, 180, and $360 \mathrm{~min}$ after the first treatment. For the behavioral studies in the object recognition task, the mixture was administered at different time points (see below).

Rolipram was freshly suspended in 5\% ethanol, $1 \%$ tylose (methyl-cellulose), and $94 \%$ distilled water on every experimental day. The following doses of rolipram were tested: $0,0.01,0.03$, or $0.1 \mathrm{mg} / \mathrm{kg}$ always in combination with the TRP- mixture ( $3 \mathrm{~h}$ before the first trial, T1). Rolipram was always administered $30 \mathrm{~min}$ before T1 (i.p. injection, dose $2 \mathrm{ml} / \mathrm{kg}$ ). 
Table 1 Composition of mixture and determination of the amino acids in gelatin-based protein $(\mathrm{mol})$

\begin{tabular}{ll}
\hline Mixture & Composition \\
\hline Protein (Solugel) in $100 \mathrm{ml}$ water & $100 \mathrm{~g}$ \\
Aspartic acid & 4.8 \\
Glutamic acid & 10.3 \\
Hydroxyproline & 11.4 \\
Serine & 3.4 \\
Glycine & 23.2 \\
Histidine & 0.8 \\
Arginine & 10.0 \\
Threonine & 2.0 \\
Alanine & 10.4 \\
Proline & 12.0 \\
Tyrosine & 0.4 \\
Valine & 2.2 \\
Methionine & 0.7 \\
Isoleucine & 1.0 \\
Leucine & 2.5 \\
Hydroxylysine & 0.9 \\
Phenylalanine & 1.1 \\
Lysine & 2.9 \\
Carbohydrate (Glucodry 210) in 80 ml water & 50 \\
KCl & 0.094 \\
CaCl2·2H2O & 2.32 \\
l-Tryptophan (TRP-group) & 0 \\
l-Tryptophan (TRP+ group) & 0.28 \\
\hline
\end{tabular}

The composition of the mixture ( $\mathrm{g}$ ) used in this experiment is described in italic. The amino acid spectrum (\%) of the Solugel protein was obtained from PB Gelatins, Tessenderlo, Belgium.

\section{Biochemistry}

For the determination of plasma amino acid levels, blood samples were taken at resting values and repeated at several points in time. Blood sampling was done via a tail-incision method (Fluttert et al. 2000). Promptly after collection of blood in sodium heparin tubes (Microvette ${ }^{\circledR}$ CB 300, Sarstedt, Germany), the samples were kept on ice. After centrifugation of the blood samples $\left(\right.$ at $4^{\circ} \mathrm{C}$ for $15 \mathrm{~min}$ at $3,000 \times g$ in a Hettich EBA 12 centrifuge), plasma was deproteinized with cups containing dry 5-sulfosalicylic acid (6 $\mathrm{mg} / 100 \mu \mathrm{l}$ plasma), and the protein was spun down. Samples were frozen in liquid nitrogen and stored at $-80^{\circ} \mathrm{C}$. Before analysis, samples were thawed at $4^{\circ} \mathrm{C}$, vortex-mixed vigorously, and centrifuged at $50,000 \times g$ in a Hereaus Model Biogufe Stratos for $10 \mathrm{~min}$ at $4^{\circ} \mathrm{C}$. From the clear supernatant, $20 \mu \mathrm{l}$ was mixed with $1,960 \mu \mathrm{l}$ water and $20 \mu \mathrm{l}$ norvaline and stored in the cooled $\left(7^{\circ} \mathrm{C}\right)$ sample compartment until analysis.

In addition to total plasma TRP, the concentrations of several other amino acids were determined with a fully automated high-performance liquid chromatography system after precolumn derivatization with ophthaldialdehyde
(OPA; Van Eijk et al. 1993). OPA amino acids derivates were quantified with fluorescence detection. The concentrations of the total plasma amino acids were expressed as micromole per liter.

\section{Object recognition memory}

The object recognition test was performed as described elsewhere (Prickaerts et al. 2002).The apparatus consisted of a circular arena, $83 \mathrm{~cm}$ in diameter. Half of the $40-\mathrm{cm}$ high wall was made of gray polyvinyl chloride, the other half of transparent polyvinyl chloride. A light bulb was switched on during testing only and provided a light intensity $(20 \mathrm{~lx})$ which was equal in the different parts of the apparatus. Two objects were placed in a symmetrical position about $10 \mathrm{~cm}$ away from the gray wall. We used four different sets of objects. The different objects were: (1) a cone consisting of a gray polyvinyl chloride base (maximal diameter $18 \mathrm{~cm}$ ) with a collar on top made of brass (total height $16 \mathrm{~cm}$ ), (2) a standard 1-1 transparent glass bottle (diameter $10 \mathrm{~cm}$, height $22 \mathrm{~cm}$ ) filled with sand, (3) a massive metal cube $(10.0 \times 5.0 \times 7.5 \mathrm{~cm})$ with two holes (diameter $1.9 \mathrm{~cm}$ ), and (4) a massive aluminum cube with a tapering top $(13.0 \times 8.0 \times 8.0 \mathrm{~cm})$. The objects could not be displaced by a rat.

In the first week, the animals were handled daily and were adapted to the procedure in 2 days; that is, they were allowed to explore the apparatus (without any objects) twice for 3 min each day. In the two following weeks, the rats were adapted to the testing and i.p. administration procedure by a saline injection $(0.4 \mathrm{ml}) 30 \mathrm{~min}$ before the first trial until they showed a stable discrimination performance, i.e., good object discrimination (a $d_{2}$ value of about 0.30 , see below) at a 1-h interval on two successive sessions. Subsequently, testing of the drugs began.

A testing session comprised two trials. The duration of each trial was 3 min. During the first trial (T1) the apparatus contained two identical objects (samples). A rat was always placed in the apparatus facing the wall in the center of the transparent front segment. After the first exploration period, the rat was put back in its home cage. Subsequently, after a delay interval, the rat was put back in the apparatus for the second trial (T2), but now with two dissimilar objects, a familiar one (the sample) and a new one. The times spent exploring each object during $\mathrm{T} 1$ and T2 were recorded manually with a personal computer.

Exploration was defined as follows: directing the nose to the object at a distance of no more than $2 \mathrm{~cm}$ and/or touching the object with the nose. Sitting on the object was not considered exploratory behavior. To avoid the presence of olfactory trails, the objects were always thoroughly cleaned with alcohol (70\%). Moreover, each object was available in triplicate so neither of the two objects from the 
first trial had to be used as the familiar object in the second trial. In addition, all combinations and locations of objects were used in a balanced manner to reduce potential biases due to preferences for particular locations or objects.

As we expected ATD to impair memory performance, we needed a delay interval at which normal rats discriminate between the novel and familiar object. Therefore, we selected a delay interval of $1 \mathrm{~h}$, as Wistar rats show good discrimination between the two objects after this interval (Rutten et al. 2006). Furthermore, we hypothesized that rolipram may reverse deficits induced by ATD in a 1$\mathrm{h}$ delay ORT. In 1 week, three testing sessions were given, with a 48-h washout period in between. Tests were always conducted on Mondays, Wednesdays, and Fridays.

In the first behavioral experiment, we investigated the effects of administration with TRP+ or TRP- mixture at different time points (i.e., $30 \mathrm{~min}, 1,3$, or $6 \mathrm{~h}$ ) before testing in the ORT. Each rat always participated in each condition, and the order of test conditions was decided at random.

The second behavioral experiment examined the effect of rolipram (30 min before $\mathrm{T} 1)$ on object recognition performance in combination with the TRP- mixture at the most effective time point (i.e., $3 \mathrm{~h}$ before T1). Thus, five treatment conditions were tested, i.e., saline, vehicle and TRP-, rolipram $0.01 \mathrm{mg} / \mathrm{kg}$ and $\mathrm{TRP}-$, rolipram $0.03 \mathrm{mg} / \mathrm{kg}$ and TRP-, and rolipram $0.1 \mathrm{mg} / \mathrm{kg}$ and TRP-. Each rat was tested in each condition, and the order of treatment conditions was decided at random. The same animals $(n=24)$ were used for both behavioral experiments; thus, control conditions (TRP+) from experiment 1 and saline from experiment 2 can be compared to each other.

\section{Statistical analysis}

\section{Biochemistry}

The mean concentrations of plasma amino acids were determined for each treatment and time condition separately. The extent of reduction (expressed in absolute values and in percentage decline from resting values) was calculated for total plasma TRP concentrations and for the TRP/ $\Sigma$ LNAA ratio. Extreme values, as determined by an extremity test (see Dixon 1959), were excluded from statistical analysis. Differences in plasma amino acid concentrations were analyzed with a general linear model, with main factor 'treatment' and repeated measure factor 'time'. Separate one-way analyses of variance (ANOVA) were performed to analyze differences between treatment conditions per time point. A post-hoc Bonferroni test was used to further characterize the differences between treatment conditions. Differences were regarded as statistically significant if $P<0.05$.

\section{Behavior}

The basic measures were the times spent by rats exploring an object during $\mathrm{T} 1$ and $\mathrm{T} 2$. Table 2 shows the measures involved in the object recognition task (Prickaerts et al. 1997). $e_{1}$ and $e_{2}$ are measures of the total exploration time of both objects during $\mathrm{T} 1$ and $\mathrm{T} 2$, respectively. $d_{2}$ was considered as index measures of discrimination between the new and the familiar objects. $d_{2}$ is a relative measure of discrimination which corrects the difference between exploring the old and the novel object for exploration activity $\left(e_{2}\right)$ and appears to be independent of the total exploration times (see Ş, $1 \mathrm{k}$ et al. 2003). In the object recognition task, results are not reliable if an animal explores both objects in the second trial for less than $5 \mathrm{~s}$ (Ş1k et al. 2003). Therefore, in every session, animals that explored less than $5 \mathrm{~s}$ in the second trial (i.e., $e_{2}<5$ ) were excluded from analysis. For all parameters, the effects of the different treatment, time, and interactions were analyzed with univariate ANOVA for the first experiment and oneway ANOVA for the second experiment. Significant effects were analyzed in more detail using the Bonferroni correction. To compare control conditions, i.e., the TRP+ ( $3 \mathrm{~h}$ before the first trial) condition of the first experiment with the saline condition of the second experiment, a $t$ test was performed. Differences were regarded as statistically significant if $P<0.05$.

\section{Results}

Plasma TRP values

The plasma TRP/ $\Sigma$ LNAA ratio is shown in Fig. 1. TRP/ $\Sigma$ LNAA levels changed over the $6 \mathrm{~h}[F(3,60)=4.92 ; P<$ $0.01]$. There was a treatment effect for TRP/ $\Sigma$ LNAA ratio $[F(2,60)=36.72, P<0.01]$. Post hoc analysis showed that the TRP- condition was significantly different than the TRP + and the saline condition (Bonferroni, $P<0.05$ ). In addition, the time $\times$ treatment interaction was also significant for the TRP $/ \Sigma$ LNAA ratio $[F(6,60)=7.80 ; P<$ 0.01]. Separate one-way ANOVA analyses for each treatment time point showed differences between treatment

Table 2 Measures involved in the object recognition test

\begin{tabular}{l}
\hline Exploration \\
\hline $\begin{array}{l}e_{1}=a 1+a 2 \\
e_{2}=a+b\end{array}$ \\
\hline$e_{1}$ is the measure of the time spent in exploring both identical objects \\
(a1 and a2) in $\mathrm{T} 1 ; e_{2}$ is the measure of the time spent in exploring \\
both the familiar (a) and new object (b) in $\mathrm{T} 2 ; d_{2}$ is the measure of \\
discrimination between the new and familiar objects.
\end{tabular}




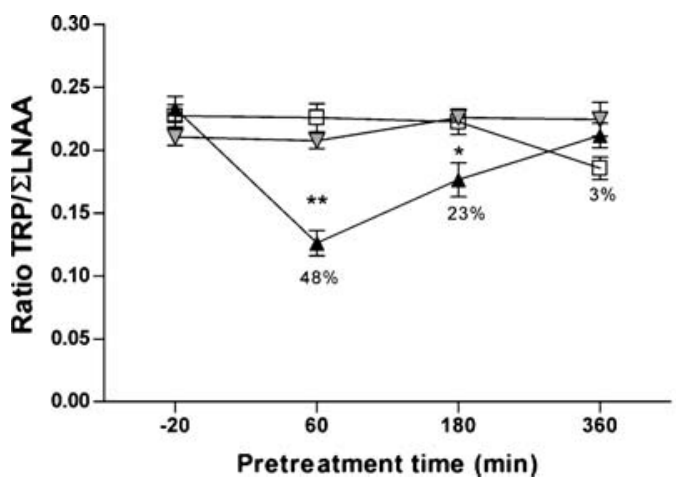

$\square$ saline

$\rightarrow-$ TRP+

$\leftarrow$ TRP-

Fig. 1 The effects of treatment time on the ratio plasma TRP/ $\Sigma$ LNAA (mean values and SEM). Percentages indicate the difference from baseline levels in the TRP- conditions. Asterisks indicate significant differences from baseline $(* P<0.05 ; * * P<0.01)$

conditions at the 1 -h time point $[F(2,17)=31.44 ; P<0.01]$ and the 3 -h time point $[F(2,16)=6.79 ; P<0.01]$. However, no differences between treatment conditions were observed at the baseline time point $(-20 \mathrm{~min})[F(2,15)=2.03$; n.s.] or the 6 -h time point $[F(2.17)=3.33$; n.s.] (see Fig. 1). Furthermore, post hoc analysis showed that the TRP/ ¿LNAA ratio of the TRP-treated animals was lower than the TRP+- or saline-treated animals at the 1-h time point (Bonferroni; $P<0.01$ ) and the 3 -h time point (Bonferroni; $P<0.05)$.

\section{Behavioral experiment 1}

The effects of ATD on ORT performance are shown in Fig. 2 and Table 3. There was a general treatment effect on ORT performance $[F(1,165)=36.44 ; P<0.01]$. In addition, a time effect was observed on ORT performance $[F(3,165)=$ $2.86 ; P<0.05]$. The time $\times$ treatment interaction was also significant for the memory performance in the ORT $[F(3,165)=4.47 ; P<0.01]$. Separate analysis per treatment condition showed that there was a significant time effect for the TRP- condition $[F(3,87)=5.41 ; P<0.01]$ in memory performance, but not for the TRP + condition $[F(3,84)=$

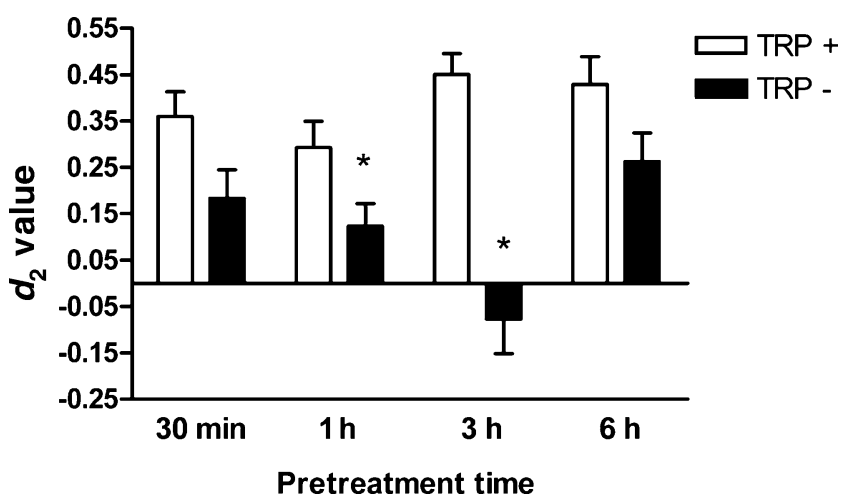

Fig. 2 The effects of treatment time of TRP+ or TRP- on the performance in object recognition task. Asterisks indicate a significant impairment in object recognition performance $(* P<0.05)$
Table 3 Exploration times in the object recognition task at baseline and after ATD

\begin{tabular}{rllll}
\hline & T1-30 min & T1-1 h & T1-3 h & T1-6h \\
\hline TRP+ & & & & \\
$e_{1}$ & $26.62(2.09)$ & $32.30(1.37)$ & $27.82(2.06)$ & $29.00(2.50)$ \\
$e_{2}$ & $33.64(2.40)$ & $49.78(3.11)^{*}$ & $28.61(2.39)$ & $28.37(2.15)$ \\
TRP- & & & & \\
$e_{1}$ & $26.97(2.11)$ & $30.39(1.78)$ & $29.29(1.66)$ & $24.98(1.53)$ \\
$e_{2}$ & $39.26(4.17)$ & $37.32(2.40)$ & $30.06(1.77)$ & $28.91(2.69)$ \\
\hline
\end{tabular}

${ }^{*} P<0.05$ (indicates significant differences to the baseline group)

1.77; $P=$ n.s.]. Post hoc analysis showed that object recognition performance was significantly impaired when the TRP- mixture was administered $3 \mathrm{~h}$ before the first trial.

Behavioral experiment 2

The effects of ATD in combination with rolipram on object recognition performance are depicted in Fig. 3 and Table 4. A dose-dependent increase in discrimination performance was observed after treatment with rolipram $[F(4,104)=$ 6.85; $P<0.01]$. Post hoc analysis showed that a dose of $0.1 \mathrm{mg} / \mathrm{kg}$ rolipram reversed the effects of TRP- treatment $(P<0.05)$. Rolipram treatment decreased exploration times in the first trial $[F(4,106)=16.24 ; P<0.01]$, but had no effect on exploration times in the second trial $[F(4,106)=$ 1.53; n.s.; see Table 4). Post hoc analysis showed that for all of the rolipram doses the exploration in the first trial was lower than the saline control condition.

A comparison between the $d_{2}$ values of the control groups of the first and second experiment (TRP $3 \mathrm{~h}$ vs

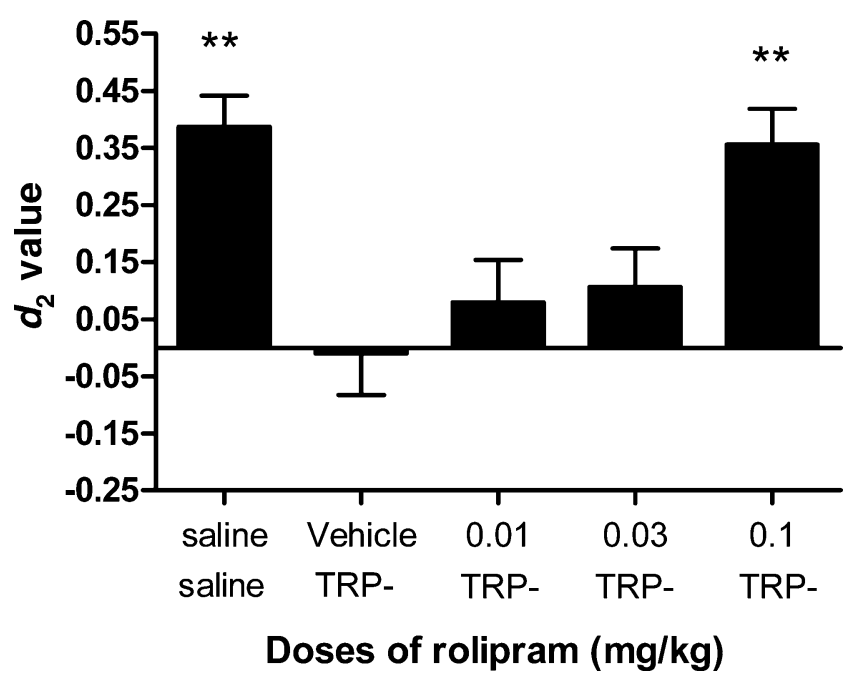

Fig. 3 The effects of rolipram treatment on ATD-induced deficits in the object recognition task. Asterisks indicate a significant difference in object recognition performance compared with the TRP- and vehicle condition $(* * P<0.01)$. The $0.1-\mathrm{mg} / \mathrm{kg}$ dose of rolipram reverses the ATD effect 
Table 4 Exploration times in the object recognition task after treatment with rolipram and TRP- mixture

\begin{tabular}{|c|c|c|c|c|c|}
\hline & $\begin{array}{l}\text { Saline } \\
\text { Saline }\end{array}$ & $\begin{array}{l}\text { Vehicle } \\
\text { TRP- }\end{array}$ & $\begin{array}{l}0.01 \mathrm{mg} / \mathrm{kg} \\
\text { TRP- }\end{array}$ & $\begin{array}{l}0.03 \mathrm{mg} / \mathrm{kg} \\
\text { TRP- }\end{array}$ & $\begin{array}{l}0.1 \mathrm{mg} / \mathrm{kg} \\
\text { TRP- }\end{array}$ \\
\hline$e_{1}$ & $28.72(2.52)$ & $26.18(1.72)$ & $19.15(1.66)^{*}$ & $18.68(1.35)^{*}$ & $12.02(1.53)^{*}$ \\
\hline$e_{2}$ & $28.73(1.42)$ & $27.43(1.80)$ & 21.68 (1.96) & $27.89(2.63)$ & $27.29(2.70)$ \\
\hline
\end{tabular}

${ }^{*} P<0.05$ (indicates significant differences to the baseline group)

saline) showed that there was no difference between these two control groups $[t(38)=0.906 ;$ n.s. $]$.

\section{Discussion}

The present study shows that acute tryptophan depletion results in reliable lowering of plasma TRP and the TRP/ $\Sigma$ LNAA ratio. When rats were administered one dose $(10 \mathrm{ml} / \mathrm{kg})$ of the TRP- mixture, depletion was maximal $(48 \%) 1 \mathrm{~h}$ after the treatment. The present data provide strong evidence that blood TRP levels predict object recognition performance and that ATD has only temporary effects on TRP levels and memory performance. When injected $3 \mathrm{~h}$ before $\mathrm{T} 1$, object recognition was maximally impaired. This is in support of the results from the blood TRP values (see above). Thus, TRP levels in the blood seem to be related with behavioral performance in rats. As previous studies have shown (Lieben et al. 2004a) a clear relation between plasma TRP and central 5-HT, these data provide further support that ATD can be used as a serotonergic-deficit model in the object recognition task.

In the study by Lieben at al. (2004a,b), two doses of the TRP- mixture $(10 \mathrm{ml} / \mathrm{kg})$ were administered, which resulted in a $70 \%$ drop of the TRP/ $/$ LNAA ratio and in memory impairment in the ORT. In contrast, the present study showed that one dose of the TRP- mixture resulted in a $48 \%$ drop in the TRP/ $\Sigma$ LNAA ratio, which was found to induce memory impairment in the ORT. These findings suggest that a $50 \%$ reduction in plasma TRP levels is sufficient to impair object memory in rats.

In the first behavioral experiment, no effects on exploration times in the ORT were observed, except from an increase in exploration time in the second trial of the $\mathrm{TRP}+1 \mathrm{~h}$ before $\mathrm{T} 1$ group. However, in the second experiment, a dose-dependent decrease in the exploration time of T1 was observed after treatment with rolipram. Previous work from our group has shown that as long as exploration in trial 1 is higher than $10 \mathrm{~s}$, a reliable discrimination index $\left(d_{2}\right)$ can be calculated (Ş, $1 \mathrm{k}$ et al. 2003). Furthermore, as can be seen when exploration times are compared to $d_{2}$ values, effects in exploration time are independent of effects in $d_{2}$ values (Ş1k et al. 2003). Rolipram is known to have some sedative side effects (at higher dosages $>0.1 \mathrm{mg} / \mathrm{kg}$ ) (Griebel et al. 1991; Silvestre et al. 1999); nevertheless, the low dosages used in the present study improved memory performance.

Rolipram has shown its pro-cognitive effects in several behavioral models. We have shown that rolipram treatment increases object memory in a time-dependent forgetting paradigm (Rutten et al. 2006). In addition, rolipram attenuated cholinergic deficits caused by scopolamine in several behavioral tasks (Imanishi et al. 1997; Rutten et al. 2006; Silvestre et al. 1999; Zhang and O'Donnell 2000). When rolipram $(0.1 \mathrm{mg} / \mathrm{kg})$ was administered in combination with the TRP - mixture (i.e., TRP $-3 \mathrm{~h}$ before $\mathrm{T} 1$ and rolipram $30 \mathrm{~min}$ before $\mathrm{T} 1$ ), we found that it reversed the effects of ATD. These are the first data suggesting that rolipram can reverse a serotonergic-induced memory deficit in rats.

Our previous study indicated that rolipram can reverse the cholinergic deficit caused by scopolamine in the ORT (Rutten et al. 2006). Remarkably, a similar dose of $0.1 \mathrm{mg} / \mathrm{kg}$ rolipram was capable of reversing the serotonergic and cholinergic deficits in the object recognition task, which might be explained by a non-specific working mechanism of rolipram. Although the underlying mechanisms of action of the memory-enhancing effects of rolipram in these models remain to be determined, the present data could be explained via an enhanced cholinergic and serotonergic turnover by rolipram (Imanishi et al. 1997; Schoffelmeer et al. 1985).

Alternatively, the effects of rolipram could also be explained in terms of only a cholinergic mechanism of action. Thus, previous studies have shown that the acetylcholinesterase inhibitor metrifonate ameliorates the effects of ATD as well and improves performance in scopolamine-deficit models of the ORT (Lieben et al. 2005). This suggests that the cholinergic and serotonergic systems act in a synergistic manner in memory performance (see Lieben et al. 2005 for a detailed discussion). Clearly, further research is needed to scrutinize the mechanism of action rolipram in the different animal models of memory.

Another mechanism of action of rolipram that could explain the present data is related to the intracellular signaling in long-term potentiation (LTP). In the hippocampus, rolipram has shown to improve LTP through activation of the cAMP/PKA/CREB pathway (Frey et al. 1993; Impey 
et al. 1996). Moreover, these mechanisms have been linked to behavioral improvement in several behavioral tasks (Barad et al. 1998; Bernabeu et al. 1997; Blokland et al. 2006; Rutten et al. 2006). Consequently, it could be argued that the present data could be explained by the effects of rolipram on the cAMP/PKA/CREB pathway. However, a recent study by our group showed that the administration time of rolipram was of critical relevance. Rolipram was only effective in the 24-h interval ORT when administered $3 \mathrm{~h}$ after T1 (Rutten et al. 2006), and the mechanism of late LTP was proposed to explain these effects. However, in the present study, a 1-h interval in the ORT was examined, in which no gene transcription or protein synthesis is required. Therefore, we assume that the cAMP/PKA/CREB pathway cannot explain these effects.

A recent PET study used radioactive rolipram as a measure for PDE4 binding and as an indirect index of cAMP signaling (Lourenco et al. 2006). Acute elevation of synaptic neurotransmitter levels (noradrenaline, 5-HT, and histamine) resulted in elevated cAMP levels that in turn elevated $(R)-\left[{ }^{11} \mathrm{C}\right]$ rolipram binding to PDE4 (Lourenco et al. 2006). According to this rationale, elevation of cAMP levels through inhibition of PDE4 can reverse cAMPmediated deficits in behavior that occur due to a shortage of 5-HT, ie, reversing the ATD-induced object recognition impairment. As rolipram non-selectively facilitates several neurotransmitter systems, a broad mechanism of action can be expected. This can be favorable because influencing multiple systems increases the likelihood that several aspects of behavior could be enhanced. This may explain previous reports that rolipram was effective in depression models (Bobon et al. 1988; Norman et al. 1992; Weishaar et al. 1985). On the downside, the broad mechanism of action increases the risks for negative side effects, e.g., emesis, sedation, and nausea.

In summary, the method of ATD can be used as a reliable method for inducing object memory impairment in rats. The selective PDE4 inhibitor rolipram was able to reverse this serotonergic deficit, which could be explained by different mechanisms of action. These data provide further support that PDE4 inhibition could be considered as a potential target to improve memory performance.

\section{References}

Bailey CH, Bartsch D, Kandel ER (1996) Toward a molecular definition of long-term memory storage. Proc Natl Acad Sci USA 93:13445-13452

Barad M, Bourtchouladze R, Winder DG, Golan H, Kandel E (1998) Rolipram, a type IV-specific phosphodiesterase inhibitor, facilitates the establishment of long-lasting long-term potentiation and improves memory. Proc Natl Acad Sci USA 95:15020-15025
Bernabeu R, Bevilaqua L, Ardenghi P, Bromberg E, Schmitz P, Bianchin M, Izquierdo I, Medina JH (1997) Involvement of hippocampal cAMP/cAMP-dependent protein kinase signaling pathways in a late memory consolidation phase of aversively motivated learning in rats. Proc Natl Acad Sci USA 94:7041-7046

Blokland A, Schreiber R, Prickaerts J (2006) Improving memory: a role for phosphodiesterases. Curr Pharm Des 12:2511-2523

Bobon D, Breulet M, Gerard-Vandenhove MA, Guiot-Goffioul F, Plomteux G, Sastre-y-Hernandez M, Schratzer M, Troisfontaines B, von Frenckell R, Wachtel H (1988) Is phosphodiesterase inhibition a new mechanism of antidepressant action? A double blind double-dummy study between rolipram and desipramine in hospitalized major and/or endogenous depressives. Eur Arch Psychiatr Neurol Sci 238:2-6

Booij L, Van der Does AJ, Riedel WJ (2003) Monoamine depletion in psychiatric and healthy populations: review. Mol Psychiatry 8:951-973

Dixon WJ (1959) Analysis of extreme values. Ann Math Stat 21:488506

Egawa T, Mishima K, Matsumoto Y, Iwasaki K, Fujiwara M (1997) Rolipram and its optical isomers, phosphodiesterase 4 inhibitors, attenuated the scopolamine-induced impairments of learning and memory in rats. Jpn J Pharmacol 75:275-281

Fernstrom JD (1981) Dietary precursors and brain neurotransmitter formation. Annu Rev Med 32:413-425

Fluttert M, Dalm S, Oitzl MS (2000) A refined method for sequential blood sampling by tail incision in rats. Lab Anim 34:372-378

Frey U, Huang YY, Kandel ER (1993) Effects of cAMP simulate a late stage of LTP in hippocampal CA1 neurons. Science 260:1661-1664

Griebel G, Misslin R, Vogel E, Bourguignon JJ (1991) Behavioral effects of rolipram and structurally related compounds in mice: behavioral sedation of cAMP phosphodiesterase inhibitors. Pharmacol Biochem Behav 39:321-323

Imanishi T, Sawa A, Ichimaru Y, Miyashiro M, Kato S, Yamamoto T, Ueki S (1997) Ameliorating effects of rolipram on experimentally induced impairments of learning and memory in rodents. Eur J Pharmacol 321:273-278

Impey S, Mark M, Villacres EC, Poser S, Chavkin C, Storm DR (1996) Induction of CRE-mediated gene expression by stimuli that generate long-lasting LTP in area CA1 of the hippocampus. Neuron 16:973-982

Lieben CK, Blokland A, Westerink B, Deutz NE (2004a) Acute tryptophan and serotonin depletion using an optimized tryptophanfree protein-carbohydrate mixture in the adult rat. Neurochem Int 44:9-16

Lieben CK, van Oorsouw K, Deutz NE, Blokland A (2004b) Acute tryptophan depletion induced by a gelatin-based mixture impairs object memory but not affective behavior and spatial learning in the rat. Behav Brain Res 151:53-64

Lieben CK, Blokland A, Șı A, Sung E, van Nieuwenhuizen P, Schreiber R (2005) The selective 5-HT6 receptor antagonist Ro4368554 restores memory performance in cholinergic and serotonergic models of memory deficiency in the rat. Neuropsychopharmacology 30:2169-2179

Lourenco CM, Kenk M, Beanlands RS, DaSilva JN (2006) Increasing synaptic noradrenaline, serotonin and histamine enhances in vivo binding of phosphodiesterase-4 inhibitor $(R)$-[11C]rolipram in rat brain, lung and heart. Life Sci 79:356-364

Norman TR, Judd FK, Burrows GD (1992) New pharmacological approaches to the management of depression: from theory to clinical practice. Aust N Z J Psychiatry 26:73-81

Park SB, Coull JT, McShane RH, Young AH, Sahakian BJ, Robbins TW, Cowen PJ (1994) Tryptophan depletion in normal volunteers produces selective impairments in learning and memory. Neuropharmacology 33:575-588 
Prickaerts J, Steinbusch HW, Smits JF, de Vente J (1997) Possible role of nitric oxide-cyclic GMP pathway in object recognition memory: effects of 7-nitroindazole and zaprinast. Eur J Pharmacol 337:125136

Prickaerts J, de Vente J, Honig W, Steinbusch HW, Blokland A (2002) cGMP, but not cAMP, in rat hippocampus is involved in early stages of object memory consolidation. Eur J Pharmacol 436:83-87

Riedel WJ, Klaassen T, Deutz NE, van Someren A, van Praag HM (1999) Tryptophan depletion in normal volunteers produces selective impairment in memory consolidation. Psychopharmacology (Berl) 141:362-369

Rose GM, Hopper A, De Vivo M, Tehim A (2005) Phosphodiesterase inhibitors for cognitive enhancement. Curr Pharm Des 11:33293334

Rutten K, Prickaerts J, Blokland A (2006) Rolipram reverses scopolamine-induced and time-dependent memory deficits in object recognition by different mechanisms of action. Neurobiol Learn Mem 85:132-138

Schmitt JA, Jorissen BL, Sobczak S, van Boxtel MP, Hogervorst E, Deutz NE, Riedel WJ (2000) Tryptophan depletion impairs memory consolidation but improves focussed attention in healthy young volunteers. J Psychopharmacol 14:21-29

Schoffelmeer AN, Wardeh G, Mulder AH (1985) Cyclic AMP facilitates the electrically evoked release of radiolabelled noradrenaline, dopamine and 5-hydroxytryptamine from rat brain slices. Naunyn Schmiedebergs Arch Pharmacol 330:74-76

Ş1k A, van Nieuwehuyzen P, Prickaerts J, Blokland A (2003) Performance of different mouse strains in an object recognition task. Behav Brain Res 147:49-54
Silvestre JS, Fernandez AG, Palacios JM (1999) Preliminary evidence for an involvement of the cholinergic system in the sedative effects of rolipram in rats. Pharmacol Biochem Behav 64:1-5

Van Eijk HM, Rooyakkers DR, Deutz NE (1993) Rapid routine determination of amino acids in plasma by high-performance liquid chromatography with a $2-3$ microns Spherisorb ODS II column. J Chromatogr 620:143-148

Weishaar RE, Cain MH, Bristol JA (1985) A new generation of phosphodiesterase inhibitors: multiple molecular forms of phosphodiesterase and the potential for drug selectivity. J Med Chem 28:537-545

West AR, Galloway MP (1996) Regulation of serotonin-facilitated dopamine release in vivo: the role of protein kinase A activating transduction mechanisms. Synapse 23:20-27

Wurtman RJ, Hefti F, Melamed E (1980) Precursor control of neurotransmitter synthesis. Pharmacol Rev 32:315-335

Zhang HT, O'Donnell JM (2000) Effects of rolipram on scopolamineinduced impairment of working and reference memory in the radial-arm maze tests in rats. Psychopharmacology (Berl) 150:311-316

Zhang HT, Crissman AM, Dorairaj NR, Chandler LJ, O’Donnell JM (2000) Inhibition of cyclic AMP phosphodiesterase (PDE4) reverses memory deficits associated with NMDA receptor antagonism. Neuropsychopharmacology 23:198-204

Zhang HT, Zhao Y, Huang Y, Dorairaj NR, Chandler LJ, O'Donnell JM (2004) Inhibition of the phosphodiesterase 4 (PDE4) enzyme reverses memory deficits produced by infusion of the MEK inhibitor U0126 into the CA1 subregion of the rat hippocampus. Neuropsychopharmacology 29:1432-1439 